\title{
Norte-Sul: Perspectivas de desenvolvimento regional no Canadá (Quebec) e no Brasil ${ }^{1}$
}

\author{
Mariana Barbosa de Souza ${ }^{2}$ \\ Yann Fournis ${ }^{3}$
}

\begin{abstract}
Resumo
Este artigo tem como objetivo refletir sobre as pesquisas realizadas na UNISC - Universidade de Santa Cruz do Sul e UQAR - Universidade do Quebec em Rimouski/Canadá, especialmente em torno dos Programas de Pós-Graduação em Desenvolvimento Regional, existentes nas duas universidades. 0 presente trabalho centra-se especificamente nas teorias de desenvolvimento regional desenvolvidas nestes dois locais: Quebec e Brasil. Primeiramente, um estado da arte será conduzido para termos uma síntese do trabalho conceitual em torno das tendências de desenvolvimento regional, tanto do Sul, quanto do Norte. A literatura mobilizou as diferentes bases de dados disponíveis na UQAR, Quebec, para compreender o significado atribuído ao conceito de desenvolvimento regional e os paradigmas que envolvem sua teoria. Em seguida, algumas reflexões serão apresentadas em torno do trabalho canadense sobre o modelo de desenvolvimento para determinar a transversalidade entre o Canadá e o Brasil e encaminhar algumas ideias para uma análise crítica da produção do espaço nas Américas, a perspectiva de habitação, bem como das atividades econômicas.
\end{abstract}

Palavras-chave: Desenvolvimento Regional. Território. Territorialização. Capitalismo.

\begin{abstract}
This article aims to reflect on research conducted at UNISC - University of Santa Cruz do Sul and UQAR University of Quebec in Rimouski/Canada, especially around the Graduate Programs in Regional Development, in the two universities. The present work focuses specifically on the regional development theories developed in these two places: Quebec and Brazil. First, a state of the art will be conducted to provide a synthesis of the conceptual work around regional development trends, from both the South and the North. The literature has mobilized the different databases available at the UQAR, especially in Quebec, to understand the meaning attributed to the concept of regional development and the paradigms surrounding its theory. Next, some reflections will be presented around the Canadian work on the development model to determine transversality between Canada and Brazil and to forward some ideas for a critical analysis of the production of space in the Americas, the perspective of housing, as well as the economic activities.
\end{abstract}

Keywords: Regional Development. Territory. Territorialization. Capitalism.

\footnotetext{
${ }^{1}$ Uma versão preliminar deste artigo foi apresentada no VIII Seminário Internacional sobre o Desenvolvimento Regional, Santa Cruz (RS), em setembro de 2017. Os autores agradecem ao governo canadense, que através do Programa Emerging Leaders in the Americas Program (ELAP), tornou possível a realização desta pesquisa.

2 Pós-doutoranda no Programa de Pós-Graduação em Geografia da Universidade Estadual de Ponta Grossa (UEPG). Doutora em Desenvolvimento Regional (UNISC). http://orcid.org/0000-0003-0126-6284. marisouza 10@hotmail.com

${ }^{3}$ Doutor em Ciência Política (Universidade de Rennes I). Professor da Universidade do Quebec (UQAR), campus de Rimouski (Canadá). Pesquisador do Centre de Recherche sur le Développement Territorial (Canadá).

yann fournis@uqar.ca
} 


\section{Introdução}

Pensar o desenvolvimento regional para além da grande divisão Norte-Sul não é uma tarefa óbvia. Por um longo tempo, a reflexão sobre o "desenvolvimento" concentrada no Sul referia-se à luta contra o chamado "subdesenvolvimento" (AZOULAY, 2002), enquanto a reflexão sobre o "desenvolvimento regional", no Norte, discutia a luta contra as disparidades espaciais dando prioridade para o desenvolvimento econômico. No entanto, esta distinção conveniente está se tornando menos válida sob o efeito da globalização: o crescimento econômico no Sul e o enfraquecimento de certos territórios no Norte oferecem um quadro mais complexo do desenvolvimento, ao ponto que alguns estão agora a considerar uma abordagem "global" do desenvolvimento regional e local (PIKE, TOMANEY, COOMBES e MCCARTHY, 2012).

Então, é neste espírito que o presente artigo se encaixa: após um resgate da história das políticas territoriais desenvolvidas no Canadá (ou mais precisamente no Quebec) e, no Brasil, pretendemos comparar brevemente teorias de desenvolvimento regional e práticas em ambos os países, para mostrar que as atuais políticas de desenvolvimento regional e local são marcadas por rupturas e contradições que refletem tentativas homólogas (mas fortemente diversas) para adaptar os territórios para o jogo da globalização contemporânea.

Contudo, os imensos territórios do Brasil e do Canadá são o espelho do aumento das contradições e limites das políticas territoriais implementadas pelos Estados para desenvolver seus territórios nacionais. Gostaríamos de demonstrar que a intervenção do Estado e o desenvolvimento regional são importantes dimensões das tentativas para responder à globalização: estas dimensões implicam construir com o Estado os arranjos territoriais, isto é, respostas coletivas para todos, que destacam a diversidade dos territórios (suas escalas, seus componentes sócio-políticos e socioculturais). Certamente, o papel do Estado no desenvolvimento regional mudou radicalmente. O Estado desempenhou uma importante função no período que compreende o pós-Segunda Guerra Mundial e a década de 1970, porquanto apresentou-se enquanto interventor em diversas áreas, especialmente na economia, para acompanhar o rápido crescimento industrial da época (LIMA e SIMÕES, 2009).

Esta "idade de ouro" do desenvolvimento regional é, contudo, menos gloriosa do que parece, porque ela é muitas vezes baseada em uma abordagem um pouco sutil de uma modernização do Estado contra os poderes locais: o desenvolvimento regional é centrado na luta contra os poderes locais, considerados como lugares de tradição, entraves à modernidade. $\mathrm{Na}$ 
década de 1990, o refluxo do Estado se pagou pelo rápido declínio das políticas regionais, mas também por um novo equilíbrio com os territórios: agora mais modestos e limitados pela globalização, o Estado intervém para a criação de políticas mais diversificadas, menos evidentes, mas cuja ambição é promover o desenvolvimento através do recrutamento de poderes locais adaptados coletivamente à globalização.

Nossa demonstração será dividida em quatro partes. A primeira recordará que, se o capitalismo e a globalização pressionam por uma convergência parcial das economias, os territórios conservam as margens de manobra essenciais quando são suportadas pelo Estado. Após analisar o desenvolvimento pelo Estado durante o período do pós-guerra, vamos examinar o papel que o Estado desempenha hoje em territórios que enfrentam globalização. A segunda parte será dedicada ao Brasil, para mostrar que ele se adaptou brutalmente à globalização, mas, apesar de uma reforma constitucional ambiciosa sobre o assunto, não pôs em prática políticas ousadas de desenvolvimento regional. O caso do Quebec, na terceira parte, mostra que dentro das suas condições, o Quebec reviveu a mobilização regional na década de 2000, após anos de dificuldade.

A última seção dará algumas pistas de comparação para recordar que a economia política de desenvolvimento dificilmente pode passar de uma análise séria do papel do Estado sobre os territórios, uma vez que ele é o principal ator capaz de fazer a ligação entre o local e o global dentro de um projeto coletivo e que dispõe de margens de manobra limitadas, mas reais para fazer - o desenvolvimento regional permanece, portanto, como uma causa profundamente política.

\section{Do desenvolvimento regional ao desenvolvimento local: ações do Estado e dos atores sociais}

O período pós-guerra foi dominado por políticas de desenvolvimento regional e de ordenamento do território que são marcadas pelos objetivos do desenvolvimento econômico dentro de uma perspectiva de integração nacional. A intervenção do Estado é crucial para o desenvolvimento econômico em consonância com a criação exógena dos mercados nacionais, quer através da manutenção direta das atividades econômicas (por intervenção do governo ou de apoio a empresas privadas) ou por um papel maior de controle e regulamentação das atividades agrícolas, industriais e de serviços (EVANS, 1998). 
De maneira geral, o período compreendido entre os anos 1950-1970 é marcado por uma concepção ambiciosa de desenvolvimento econômico, centrado na polarização da economia entre os espaços e o das economias externas (dentre os teóricos destacamos Perroux (1967), Boudeville (1970), Myrdal (1957), Hirschman (1958) e North (1977). O processo de desenvolvimento econômico é visto como fundamentalmente instável, o que justifica a intervenção do Estado em favor o desenvolvimento regional através de políticas públicas específicas. Muitas vezes inspirado pela teoria dos polos de crescimento, as diferentes políticas procuraram resolver a questão das disparidades regionais resultantes do mesmo processo de desenvolvimento econômico no espaço. Estas políticas passam essencialmente por instituições públicas de planejamento que ampliam a jurisdição do Estado: o desenvolvimento pela industrialização implica um novo modelo de gestão do território pelo Estado, em que o objetivo de superar o subdesenvolvimento não pode passar pelo empoderamento dos atores locais.

Esta época também é um período de triunfo das políticas top-down, dos tecnocratas e da racionalização do uso do espaço - em suma, de uma modernização forçada e custodiada pelo Estado. Todos são marcados por uma abordagem centrada no Estado, elitista e descendente de desenvolvimento: territórios e os seus representantes são marginalizados pelos princípios e métodos do desenvolvimento, seja econômico (industrialização), social (cidadania nacional) ou políticos (políticas centrais) (PIKE; RODRÍGUEZ-POSE; TOMANEY, 2006). Mas o período seguinte é muito diferente.

Tabela 1 - Períodos do desenvolvimento

\begin{tabular}{|c|c|c|}
\hline Worid framework & Deveiopmentalism (1940s-1970s) & Globalism (1970s-) \\
\hline Political economy & $\begin{array}{l}\text { State regulated markets } \\
\text { Keynesian public spending }\end{array}$ & Self-regulating markets (Monetarism) \\
\hline Social goals & $\begin{array}{l}\text { Social entitlement and welfare } \\
\text { Uniform citizenship }\end{array}$ & $\begin{array}{l}\text { Private initiative via free markets } \\
\text { Identity politics versus citizenship }\end{array}$ \\
\hline Development (model) & $\begin{array}{l}\text { Industrial replication } \\
\text { National economic management } \\
\text { (Brazil, Mexico, India) }\end{array}$ & $\begin{array}{l}\text { Participation in the world market } \\
\text { Comparative advantage } \\
\text { (Chile, New Zealand, South Korea) }\end{array}$ \\
\hline Mobilising tool & Nationalism (post-colonialism) & $\begin{array}{l}\text { Efficiency (post-developmentalism) } \\
\text { Debt and credit-worthiness }\end{array}$ \\
\hline Mechanisms & $\begin{array}{l}\text { Import-substitution industrialisation (ISI) } \\
\text { Public investment (infrastructure and energy) } \\
\text { Education } \\
\text { Land reform }\end{array}$ & $\begin{array}{l}\text { Export-oriented industrialisation (EPO) } \\
\text { Agro-exporting } \\
\text { Privatisation, public and majority-class austerity } \\
\text { Entrepreneurialism }\end{array}$ \\
\hline Variants & $\begin{array}{l}\text { First World (freedom of enterprise) } \\
\text { Second World (central planning) } \\
\text { Third World (modernisation via developmental alliance) }\end{array}$ & $\begin{array}{l}\text { National structural adjustment (opening economies) } \\
\text { Regional freotrade agreements } \\
\text { Global economic and environmental management }\end{array}$ \\
\hline $\begin{array}{l}\text { Local and } \\
\text { regional } \\
\text { dimension }\end{array}$ & $\begin{array}{l}\text { National spatial policy } \\
\text { Economic and social focus } \\
\text { Growth redistribution }\end{array}$ & $\begin{array}{l}\text { Supranational and devolved (subnational, regional } \\
\text { and local) policy and institutions } \\
\text { Economic competitiveness focus } \\
\text { Regeneration }\end{array}$ \\
\hline
\end{tabular}

Fonte: elaborada pelos autores. 
A partir de 1970, começa uma nova era do desenvolvimento, menos submisso ao estado na crescente globalização dos territórios. Diferentes variáveis se combinam para causar uma retração do Estado (crise e conservadorismo fiscal, falha parcial de legitimidade e eficácia, descentralização e internacionalização). O momento já não é de integração nacional, como tal, mas sim de adaptação dos territórios à economia nacional compreendendo a dinâmica da globalização. Muito criticado e agora mais modesto, o Estado é mais sutil e privilegiará as políticas públicas de um novo tipo - que é muitas vezes resumido sob o termo "desenvolvimento local".

Sem repetir aqui o bordão de uma noção amplamente criticada (e com razão), observamos apenas que o estado está de volta a incentivar iniciativas dos territórios (dos atores econômicos, mas também sociais), para que eles gerem suas próprias dinâmicas de desenvolvimento endógeno. Se, de alguma forma, o jogo ficou mais homogêneo do que era antes (uma vez que as restrições da economia global raramente são contestadas), o essencial sem dúvida que o novo papel de vigia tomado pelo Estado (que continua presente, mas na maior parte indiretamente) perturba o desenvolvimento regional: deve agora ser visto como um apoio à diversidade de forças presentes nos territórios (diversidade como evidenciado pelas muitas teorias para explicar: sistemas produtivos locais, ambientes inovadores, Terceira Itália, neoregionalismo, entre outras).

Consequentemente, as políticas de desenvolvimento se transformaram radicalmente: elas agora pretendem homogeneizar o espaço por medidas substanciais para explorar a diversidade dos territórios, estabelecendo procedimentos favoráveis para a mobilização local dos atores econômicos e, em menor medida, sociais. P. Duran e J.-C. Thoenig (1996), a este respeito, falam de "componente político", que visa conferir aos atores territoriais o poder de determinar quais são as suas questões prioritárias, também quais as soluções e atores pertinentes para a resolução ${ }^{4}$. Assim, as novas políticas de desenvolvimento realmente assumiriam a forma de dispositivos de ação pública institucionalizados pelo Estado, cujos atores podem (ou não!) se agarrar (e seguimentos de excelência no Quebec) para se mobilizar em função dos objetivos propostos pelo Estado. Ele capta essas novas políticas bottom-up apresentando uma

\footnotetext{
4 “Une politique constitutive édicte des règles sur les règles ou des procédures organisationnelles. Elle ne dit pas quelle est la définition du problème et quelles sont les modalités de son traitement opérationnel. Elle se contente de définir des procédures qui servent de contexte d'action sans que soit présupposé pour autant le degré d'accord et d'implication des acteurs retenus. Des scènes d'action et des territoires sont créés qui offrent des positions d'échange et d'ajustement et que la puissance publique investit de valeurs, de légitimité ou de cognition. La politique constitutive délègue le traitement du contenu" (DURAN e THOENIG, 1996, p. 601).
} 
configuração política muito diferente das "velhas" políticas regionais: os atores locais são o centro das políticas, dos seus princípios, dos seus termos (ver tabela).

No entanto, esta nova configuração está longe de ser apolítica, desde o fim da hegemonia do Estado no desenvolvimento regional reabriu o jogo em favor de atores territoriais, que estão competindo agora para gerar políticas públicas na base - em função das regras estabelecidas pelo centro. Agora, vamos ver que todos os Estados não são iguais a este respeito: enquanto alguns favorecem os atores territoriais mais poderosos (começando com os municípios), outros tentam o contrário, expandir o círculo de decisores e atores locais através da criação de órgãos locais e políticas regionais pluralistas.

De qualquer forma, os casos das políticas regionais no Brasil e no Canadá dizem muito a respeito da questão mais geral de desenvolvimento, desde o período conhecido como "trinta gloriosos". Há muito tempo o Estado conta com uma concepção centrada nele próprio e elitista de desenvolvimento nacional para gerir sua relação com os territórios por intermédio do desenvolvimento econômico. A partir de agora, o "velho" desenvolvimento regional foi substituído por uma concepção territorial, ascendente e plural das políticas de desenvolvimento, que deve favorecer uma adaptação econômica de cada espaço à globalização.

Agora, estas duas configurações políticas exigem uma economia política do desenvolvimento regional: no Brasil e no Canadá, as forças mobilizadas pelas novas políticas não são as mesmas, refletem a diversidade dos territórios e os efeitos elitistas dirigidos pelo Estado nas estratégias de desenvolvimento.

\section{0 caso do Brasil: um desenvolvimento a-regional?}

As políticas de desenvolvimento regional no Brasil são marcadas pela história e pela geografia: defrontado a um território imenso estreitamente inserido no seu contexto continental, o Brasil, durante a proclamação da República em 1889, tomou a forma de um Estado Federal, mais recentemente confirmada pela Constituição da República Federativa do Brasil (CRFB/1988), promulgada em 05 de outubro de 1988, composta pelos Estados federados ou Estados-membro, Territórios Federais e Distrito Federal (SILVA, 2012). Como nota Bulos (2012, p. 915), o resultado é uma configuração de poderes particulares: o poder é organizado a partir de um "movimento centrífugo", porque o Estado unitário se "descentralizou para formar unidades autônomas de poder". 
No Brasil, a ação do Estado intervencionista visava destinar os investimentos às zonas desfavorecidas ou áreas de alto risco. Esta ação do Estado, com base em diretrizes estabelecidas pela Comissão Econômica das Nações Unidas para a América Latina e o Caribe (CEPAL) (FURTADO, 2007), é, apesar de profunda originalidade uma abordagem clássica de desenvolvimento. Ou seja, se a industrialização é a única maneira de superar a pobreza, o "livre mercado" não pode reduzir a pobreza, tornando-se necessário que o Estado agisse como planejador em diferentes áreas, econômica (organização da produção) e sociais (como educação, saúde, habitação). A criação de planos e ações de desenvolvimento seria decisiva para o desenvolvimento econômico, a implementação do modelo de intervenção do Estado e seu caráter institucional. É neste contexto que as políticas regionais vão surgir, não sem contradições.

De acordo com Acselrad (2008), o desenvolvimento no Brasil tem duas fases. A primeira delas é anterior a 1960, não havia uma estratégia de desenvolvimento e as regiões brasileiras não possuíam qualquer ligação. Nesta época existiam pequenas interações para facilitar a integração das áreas de produção dos fluxos globais do comércio. Após este período, no entanto, o desenvolvimento de um mercado interior é afirmado, favorecido por políticas regionais que são destinadas principalmente a estimular a industrialização, reduzir conflitos de terra no Nordeste e colonizar fronteiras por razões econômicas, mas também geopolítica. Várias políticas em particular são implementadas, assentadas sobre as principais teorias internacionais de desenvolvimento, que se caracterizaram no século XX. Desde os anos 1970, o desenvolvimento regional tem um novo foco, mais endógeno, mas a prioridade brasileira é em detrimento de uma coerência do desenvolvimento nacional, a fim de orientá-lo para o mercado global - que vai se tornar uma realidade na década de 1990.

No entanto, neste quadro bastante pessimista em que as políticas regionais parecem sempre subordinadas a imperativos nacionais e globais, a década de 1980 é uma exceção parcial, relacionada com a promoção dos objetivos territoriais com a promulgação da CRFB/1988. Depois de vinte anos de luta contra o regime militar implantado no Brasil em 1964, o processo brasileiro de democratização culminou com a promulgação da CRFB/1988. Isso desencadeia uma descentralização dos poderes da União, conferindo aos Estados-membro e aos municípios maior autonomia, sem hierarquia definida entre os entes federativos. Esta autonomia determina pela CRFB/1988 faz referência ao autogoverno, autoadministração e auto-organização - dentro dos limites permitidos pela soberania da União. Assim, a repartição de competências na federação brasileira é vertical (com algumas competências divididas) entre os entes federativos, que 
dispõem de jurisdição sobre seu território espacial (SENRA, 2009). Formalmente, este novo quadro jurídico é muito dinâmico, implicando um reforço nas relações intergovernamentais, mas também uma política de ordenamento do território.

As relações entre os entes da federação são, de acordo com a CRFB/1988, fundadas na cooperação entre seus membros e incluem as regiões, destacadas no texto constitucional e reconhecidas administrativamente, nos artigos 25, § 3ㅇ, 43, 151 e 159 (BRASIL, 1988). Destacamos as regiões metropolitanas, órgãos funcionais (bacias hidrográficas) microrregiões geográficas, entre outros, nos quais as decisões sobre as questões de pertinência social, meio ambiente, desenvolvimento urbano, necessitam de decisões compartilhadas. De maneira mais geral, as disposições reorientam o desenvolvimento regional para os Estados-membro, que podem estabelecer regiões metropolitanas, aglomerações urbanas e microrregiões, a fim de possibilitar o planejamento, bem como a criação de políticas de interesse comum, conforme prevê o artigo 25 da CRFB/1988 (BRASIL, 1988). Os municípios não podem ser esquecidos: conforme o artigo 30 da CRFB/1988, compete aos municípios a promoção da ordenação territorial, respeitando suas fronteiras, por meio de ações planejadas de controle de uso, parcelamento e ocupação do solo urbano (BRASIL, 1988). Em qualquer caso, a relação entre os entes federativos deve ser cooperativa.

Em seguida, a redução das desigualdades regionais é reconhecida na CRFB/1988 como um objetivo fundamental da federação brasileira. O artigo 3. faz da redução das desigualdades regionais um dos objetivos fundamentais da República5: "erradicar a pobreza e a marginalização e reduzir as desigualdades sociais e regionais" (BRASIL, 1988). Estes princípios estão consagrados nas políticas previstas por vários dispositivos constitucionais ambiciosos e deverão convergir para uma outra pretensão constitucional, já que nos termos do artigo 21 da CRFB/1988, a União é responsável pela criação de plano nacionais e regionais de ordenamento do território e desenvolvimento econômico social, além de determinar diretrizes para o desenvolvimento urbano.

Essa nova arquitetura parece ser capaz de conduzir um novo rumo para a política regional no Brasil. Infelizmente, o que é notável, quase trinta anos após a promulgação da CRFB/1988 é que a maioria dos instrumentos de desenvolvimento regional no Brasil não foram

\footnotetext{
${ }^{5}$ Alguns autores, como Etges (2019), entendem que as desigualdades regionais são consequência do próprio modo como a lógica de produção capitalista se expressa. Assim, as desigualdades regionais não deveriam ser vistas como obstáculos a serem superados, mas sim como particularidades que, quando potencializadas, funcionam como possibilidade endógena de desenvolvimento regional.
} 
implementados pelo Poder Executivo ou regulamentados pelo Congresso, que mantêm também a tendência à centralização drástica dos recursos e decisões em nível federal, o que se traduz como entrave ao desenvolvimento regional. Isto se tornou mais evidente quando os governos redirecionaram sua agenda na década de 1990: a prioridade era o ajuste neoliberal para o novo contexto global - o que na prática, para a América Latina, implica no respeito ao "Consenso de Washington", aos "imperativos" da internacionalização do capital financeiro e às prioridades do Fundo Monetário Internacional (FMI).

No início dos anos 1990, o presidente Collor defende abertura da economia brasileira ao capital estrangeiro, a promoção da competitividade empresarial e a privatização de empresas públicas. Neste contexto, o desenvolvimento regional é uma variável de ajuste: suas ações visam projetar a economia nacional para o mercado mundial, com os objetivos principais de aumentar as exportações e de fortalecimento institucional das capacidades locais. O governo de Fernando Henrique Cardoso (FHC), com início em 1994, continua com a ideia lançada no governo anterior: enquanto o governo prioriza a estabilidade monetária e várias políticas setoriais de desenvolvimento, o financiamento de programas regionais e sociais é muito reduzido (IPEA, 1999). Esta tendência foi parcialmente compensada pelo suporte federal para novas dinâmicas, mas ainda contraditórias (SENRA, 2009).

Existe um dinamismo local inegável no Brasil. Para Bulos (2012), a CRFB/1988 inovou na direção do reconhecimento dos municípios, dotados de autonomia política e administrativa. 0 município apresenta-se como um espaço apropriado para o fomento da cidadania, mormente ante a proximidade que detém com os que necessitam de soluções concretas para os entraves cotidianos (MAGALHÃES, 1999). No entanto, isso parece multiplicar as tensões e possivelmente os conflitos entre a União, os Estados-membro e os municípios. Em particular a "guerra fiscal" afeta não somente os Estados-membro, mas também os municípios. Em segundo lugar, o Estado encorajou programas de desenvolvimento local, com o Conselho do Programa Comunidade Solidária elaborou o Comunidade Ativa, com a finalidade de promover o desenvolvimento local integrado e sustentável.

Para que a ideia fosse concretizada, foram criadas as Redes DLIS - Desenvolvimento Local Integrado Sustentável e a Rede de Informações para o Terceiro Setor-RITS. A Rede DLIS é aberta a pessoas e organizações de todos os setores, sociedade civil, governo e iniciativa privada, e tem o objetivo de gerar visibilidade para as iniciativas concretas, facilitar articulações entre atores e fortalecer ações de desenvolvimento local. A Rede apoiou a criação de fóruns de 
desenvolvimento local ou outras novas institucionalidades participativas (SENRA, 2009). Finalmente, a política regional brasileira termina os anos 1990 com base quase que exclusivamente em incentivos fiscais e financeiros para as empresas e sendo coordenada apenas por instituições relacionadas ao aparato estatal, com raros movimentos de outros atores (BANDEIRA, 2013).

Nestas condições, entendemos aqueles que usam um julgamento reduzido sobre o período. A CRFB/1988 representou um passo importante na redemocratização do Brasil, sem negligenciar questões específicas, tais como a descentralização, a participação social e questões de desenvolvimento e ambientais, temas mobilizados pelas políticas públicas setoriais que foram submetidos ao impacto do choque de um contexto de crise econômica e exclusão social. Mas o Estado não foi à altura dos desafios, se bem que alguns estimam que ele sacrificou o desenvolvimento regional à globalização: na década de 1990, "a globalização reforçou a tendência para áreas de especialização" e, ao mesmo tempo, "o estado abandonou sua ação como um indutor do desenvolvimento" (ACSELRAD, 2008, p. 53), privilegiando uma terapia de choque para setores produtivos "de repente expostos à concorrência internacional, num contexto grandes mudanças tecnológicas e organizacionais" (BRANDÃO, 2004, p. 68).

Quanto ao Brasil, pode-se dizer que a década de 1980 representou uma queda das políticas de desenvolvimento regional, sobretudo (e paradoxalmente) após a promulgação da CRFB/1988, que deu mais importância aos níveis nacional e local (municípios). As políticas eram criadas e implementadas de cima para baixo e possuíam na escala nacional sua razão principal, ignorando as particularidades regionais (MACEDO e COÊLHO, 2016).

Mais recentemente, a Política Nacional de Desenvolvimento Regional, o Brasil retomou a iniciativa de pensar políticas públicas a partir da escala nacional, porém, levando em consideração as particularidades regionais e não ignorando as iniciativas locais, tomou a iniciativa de pensar em políticas públicas em nível nacional, mas tendo em conta as iniciativas locais regionais ${ }^{6}$. Assim, o primeiro mandato de Lula (2003-2006) anunciou uma política nacional de

\footnotetext{
${ }^{6}$ De acordo com o documento original: “A PNDR exige uma abordagem das desigualdades regionais em múltiplas escalas. A visão tradicional que resumia o problema regional brasileiro ao atraso relativo das Regiões Norte e Nordeste, vistas de forma homogênea, não reconhece nem a existência de dinâmicas sub-regionais diversas em todas as macrorregiões, nem a necessidade de coordenação de ações, com os entes federados e com a sociedade civil, em níveis que vão do intraurbano ao mesorregional. A ação da Política não se limita à alocação equânime de recursos de origem federal nos territórios; ela reconhece as desigualdades regionais em múltiplas escalas de intervenção e orienta políticas e programas que promovam o desenvolvimento territorial. Busca, ainda, articular políticas setoriais para regiões, sub-regiões prioritárias, sobretudo as de baixa renda, estagnadas e com dinamismo recente, segundo a tipologia proposta pela PNDR." (MINISTÉRIO DA INTEGRAÇÃO, 2007, p. 13-14).
} 
desenvolvimento regional, envolvendo diferentes escalas de ação política (valorizando sensivelmente o nível local) e com uma preocupação particular para as regiões periféricas, como o Nordeste semiárido e a Amazônia (MACEDO e COÊLHO, 2016).

\section{0 caso do Quebec no Canadá: a região pela política?}

No Canadá, o pós-guerra foi um período de afirmação do Estado na luta contra as disparidades no espaço. Após a concessão da autonomia à Confederação canadense em relação à Grã-Bretanha, desde a sua criação em 1867, o desafio para o Estado em meados da década de 1940 foi o de incentivar o surgimento de uma identidade canadense que unificasse as diferentes províncias. Esta ação requeria o estabelecimento de um Estado-Providência dinâmico, de políticas keynesianas mais ou menos eficazes e, a partir dos anos 1960, através de políticas regionais, reequilibrar o crescimento em favor dos territórios em dificuldade (Políticas Nacionais Protecionistas, equalização, políticas de desenvolvimento regional) (BRODIE, 1996).

Diante da atração crescente da economia dos Estados Unidos no contexto de um “fordismo permeável" (JENSON, 1989), o Canadá tenta estabelecer as condições para um desenvolvimento econômico autossustentável, bastante clássicos dos arranjos fordistaskeynesianos (KLEIN, 1999). Neste contexto, as políticas regionais complementam as políticas keynesianas por assegurar uma homogeneização territorial das condições da produção e do consumo de massa em tom menor e focado nas únicas regiões em dificuldade, excluídas do crescimento fordista (LÉVESQUE e MAGER, 1995).

A luta contra as disparidades regionais foi uma prioridade do governo canadense na década de 1960, quando os desequilíbrios de desenvolvimento sob a influência do comércio continental e as estratégias das provinciais ameaçam a unidade nacional (JENSON, 1989). A partir de 1960, o governo federal aplicou progressivamente um audacioso plano de desenvolvimento rural, que rapidamente se expandiu para todas as regiões em dificuldade. Os principais instrumentos utilizados foram a lei federal sobre o desenvolvimento rural e desenvolvimento agrícola (ARDA), em 1961; o Fundo de Desenvolvimento Econômico Rural, em 1966; e, o programa de isenções fiscais, em 1963. O objetivo não era apenas para afirmar a mobilização do estado, um Ministério de Expansão Econômica Regional (MEER) foi criado em 1969, mas também para fomentar parcerias entre os diferentes governos através de várias medidas e acordos de desenvolvimento que delineiam um processo de planejamento. 
Relançadas pelo governo Trudeau na década de 1960, essas políticas estavam na agenda até 1980, mas a sua implementação, no entanto, experimentou algumas dificuldades, como ilustrado pelo caso do Leste do Québec - que prontamente condenou uma política regional projetada no modo top-down. O Leste do Quebec é um território rural periférico em grande dificuldade desde os anos 1950. Alia o êxodo rural ao declínio econômico, ele é objeto de uma mobilização coletiva de base a partir dos anos 1960. Em articulação com as políticas regionais federais e provinciais, essa mobilização resultou em uma tentativa de planejamento regional original e ambicioso, que visou gerar uma mobilização popular em torno do uso racional dos recursos e do espaço.

Apesar da qualidade do planejamento proposto e do escopo participativo original, o Escritório de Ordenamento do Leste do Québec teve pouco sucesso. Rapidamente contestado, ele constatou uma falha precoce, que abortou qualquer política de ordenamento regional - pelo menos para o Quebec. Sob a impulsão da Província e em parceria com o federal, um embrião da arquitetura regional foi criado, com a criação de regiões em 1966 e do Gabinete de Planejamento e Desenvolvimento de Quebec (OPDQ - I'Office de Planification et de Développement du Québec) em 1969 e que vai participar das diferentes políticas regionais nos anos 1970. Apesar de um financiamento substancial, esta política permaneceu incompleta e não resistiu à crise da década de 1980: enquanto o governo federal reduzia os organismos centrais (fusão do MEER em 1982 e desmantelamento em 1987 em favor de agências de desenvolvimento), o governo provincial abolia o OPDQ, em 1993. Agora é o momento para as políticas bottom-up, menos generosas financeiramente, mas politicamente mais sutil.

Com efeito, as políticas descendentes de desenvolvimento são rapidamente confrontadas pela resistência da sociedade quebequense. Elas irão culminar no Leste-du-Québec, quando a contestação do plano do BAEQ gerou uma contra mobilização, com a "Operações Dignidade" que reivindicavam políticas de desenvolvimento menos centradas nas capacidades do Estado e mais no apoio das iniciativas de desenvolvimento comunitário (para o desenvolvimento florestal em zonas rurais). De modo mais geral, estes anos foram, em áreas rurais e urbanas, de uma recomposição das relações entre os governos (federal e provincial) e os meios territoriais: depois de empurrar o intervencionismo quebequense dos anos 1960, chegou a hora de um equilíbrio entre os movimentos comunitários e a ação pública.

Em torno de um discurso de participação popular (muito crítico) na década de 1970, seguido da participação cidadã (mais moderada) na década de 1980, os grupos locais 
reivindicavam uma co-construção de questões e de programas públicos com o Estado. Em termos de desenvolvimento econômico (urbano e rural) e de prestação de serviços sociais, o Estado reconhece, institucionaliza e financia as organizações do movimento comunitário, que participavam da gestão dos problemas sociais (como os relacionados à saúde, habitação e violência sexual), ou seja, as questões relacionadas com a vida em sociedade (CÔTÉ e SIMARD, 2011). Isso também vale para o desenvolvimento territorial, em que a cooperação entre o Estado e os organismos comunitários e de planejamento compõem o que alguns autores chamam de "modelo quebequense" de governança (CÔTÉ, LÉVESQUE e MORNEAU, 2007; Hamel e JOUVE, 2006). Encorajados e regulados pelo Estado, os grupos comunitários participavam da concertação e das negociações em fóruns públicos (SIMARD e CÔTÉ, 2010).

Os agentes governamentais se tornam seus porta-vozes, em nome tanto dos dirigentes quanto dos excluídos, restringindo de fato esse espaço público deliberativo apenas às mesas de concertação. Isso representa um freio para a emergência de inovações sociais em escala regional que não correspondam aos temas, aos interesses ou às prioridades dessas mesas de concertação ou dos dirigentes regionais. Sabe-se, na verdade, que as inovações sociais emergem, em muitos casos, de movimentos ou de esferas sociais distintas e muitas vezes reativas às ideias, aos discursos e às regras do momento (CÔTÉ e SIMARD, 2011).

A ampliação dos mecanismos de concertação não deveria ser subestimada, ainda mais porque o seu fortalecimento se confirmou ao ponto de substituir progressivamente a política regional descendente. Embora fosse frágil (com o fracasso das cúpulas regionais na década de 1980 e a supressão do OPDQ em 1993), os governos implementavam novas políticas públicas com base na ativação das dinâmicas sociais dos territórios. Inicialmente identificada em torno dos organismos federais de desenvolvimento local, esta tendência se tornou evidente com a reforma Picotte de 1992 que, em período de restrição orçamentária, apostou na participação dos meios de comunicação para incorporar projetos regionais. Inversamente à relação tradicional entre Estado e os territórios, esta reforma não deve ser compreendida como uma retirada do Estado, mas sim como uma recomposição de sua parte: ele quer "acompanhar" ao invés de criar o desenvolvimento (KLEIN, 1999) e continuou a ser muito presente nos territórios.

Por meio de políticas sociais, de políticas educacionais e de políticas de desenvolvimento econômico, o Estado passou a confiar sistematicamente em organizações comunitárias para a implementação dos seus objetivos. O fim dos anos 1990 vai mostrar que essa retirada é mais aparente do que real: pela reforma regional e local, de 1998, o governo provincial estimulou as dinâmicas de concertação nos dois níveis para provocar uma forma de reordenação entre as 
inúmeras organizações locais e regionais - constituindo de uma certa maneira o apogeu de uma aplicação territorial do modelo quebequense.

Definitivamente, as políticas substanciais de desenvolvimento regional entraram em colapso nos anos 1980-1990, suscitadas por uma recomposição significativa do papel do Estado nos territórios. Além da retirada financeira (em nome da austeridade que era necessária nos anos de 1990 e 2010), no entanto, é difícil concluir que o Estado é menos presente do que antes, porque ele encorajou dinâmicas comunitárias ascendentes (múltiplas e desordenadas), reforçando a sua capacidade de controle.

O resultado foi uma política territorial (mais que regional) fundamentalmente ambivalente, na qual o Estado governava a sociedade, cultivando o tecido comunitário, conformando-o aos seus objetivos setoriais, para estabelecer e implementar as suas políticas e capacitá-lo para a mercantilização. Esta parceria é um compromisso estranho entre os objetivos do Estado e dos grupos comunitários, que dão lugar a relações, por sua vez, tensas e duráveis. 0 outro lado é conhecido, uma vez que colocou o desafio da governança à distância dos territórios, onde o encorajamento da mobilização comunitária também era um mecanismo de controle burocrático sobre os territórios.

No entanto, este modelo de governança territorial não era sem mérito, em particular pelo fato de ser pluralista, conduzindo à popularização das temáticas progressistas: os grupos mobilizados eram incentivados a participar das concertações em torno das instituições públicas, em torno da sua grande diversidade de temas (meio ambiente, economia social, desenvolvimento comunitário, a igualdade de direitos entre homens e mulheres, as discussões sobre a segurança alimentar, etc.). Como nota Fontaine (2005, p. 337), estas "politiques et ces modèles agissent comme outils collectifs de traitement de problèmes auxquels les groupes humains sont confrontés, assurant que des ressources seront dirigées vers leur traitement ${ }^{7 \prime \prime}$ conciliavam, portanto, a legitimidade e o financiamento do Estado, por um lado, e a experiência técnica e empírica dos grupos comunitários por outro.

\footnotetext{
7 "políticas e modelos agem como ferramentas coletivas no tratamento de problemas que os grupos humanos enfrentam, garantindo que os recursos serão direcionados para o seu tratamento". (Tradução nossa).
} 


\section{A economia política do desenvolvimento regional no Brasil e no Quebec (Canadá): da política regional à política da sociedade civil}

Optamos por não tratar desta última parte como considerações finais ou conclusão porque o tema enseja novos escritos e novas pesquisas e a comparação das políticas de desenvolvimento regional no Brasil e no Quebec recorda que, mesmo que exista uma globalização, há muitas maneiras radicalmente diferentes, para responder à questão. A priori, as convergências entre os dois países são massivas: são estados do Novo Mundo, de forma federal, que precisam lidar com a inserção internacional precoce e com um extenso território periférico marcado por disparidades. Isto resultou em um desafio estrutural comum: a exigência de um projeto de integração territorial vinculado ao desenvolvimento (em grande parte centrado historicamente na exportação de recursos naturais) e desenvolvimento regional (para lutar contra as desigualdades e disparidades espaciais).

Uma primeira análise confirma que a este quadro econômico comum foi adicionada, na década de 1960, a ambição de uma nova política, de um desenvolvimento centrado no Estado bastante comum na época (PIKE; RODRÍGUEZ-POSE; TOMANEY, 2006), que entrou em crise na década de 1970. E parece que entrou em colapso na década de 1990, antes de experimentar uma recuperação na década de 2000. No entanto, a ligação entre o desenvolvimento e o desenvolvimento regional não é automática, tal como indicam os destinos contraditórios das políticas regionais: se as políticas de desenvolvimento regional moldaram e moldam o espaço do Quebec e do Brasil, existem diferenças significativas entre elas. Uma das mais evidentes é o estilo das políticas de desenvolvimento regional, em grande parte opostas.

No Brasil, as políticas públicas de desenvolvimento regional são tradicionalmente inspiradas por uma abordagem top-down, ou seja, de cima para baixo, enquanto que no Quebec, a política de participação comunitário assegura aos territórios uma certa influência nas políticas públicas (seguidamente em nível de implementação, com foco na própria comunidade, enquanto que as opções de investimento, financiamento e objetivos retornam para o estado). Há, porém, outra mais discreta: enquanto mobilizações locais são bastante limitadas no Brasil por um discurso de gestão e eficiência, as grandes empresas internacionais são privilegiadas pelo Estado no planejamento do desenvolvimento.

O modelo quebequense de desenvolvimento se caracteriza pela centralidade do discurso participativo e pluralismo dos componentes da comunidade local (empresários, mas também a economia social, cultura, meio ambiente, etc.). Dito isto, as recentes reformas do Partido Liberal 
de Quebec (que removeu as regiões em 2015) e as ambições do governo Lula no início dos anos 2000 indicam que estas estruturas estão evoluindo como parece: elas permanecem objetos de luta entre os governos, liberais ou progressistas.

Insistimos na dimensão política da economia política do desenvolvimento regional. Sabemos que foi analisado e é resultado histórico da relação entre os vários atores que disputam espaço (o Estado, classes sociais, o capital), resultando em uma organização específica do espaço, uma regionalização (HARVEY, 1985). Contudo, o Estado provavelmente não é como outro ator em tais situações que determinam os arranjos territoriais: ele continua a ser ator por excelência, pelos seus recursos substanciais (definição de objetivos e alocação de recursos financeiros) e processual (a seleção e mobilização dos atores - não apenas territoriais).

Para retomar a proposta de Boisier (1996, p. 113), o desenvolvimento regional evolui de fato em um cenário que implica simultaneamente um processo de abertura exterior (econômica e impulsionada pela globalização) e um processo de abertura interna (política e impulsionada pela descentralização). Mas esta articulação entre global e local faz das margens de manobra importantes limites, especialmente em termos de equidade, participação, adaptação e resiliência. Outrossim, quem além do Estado pode efetuar este tipo de escola para regular a relação entre o global e o local? No entanto, a novidade do período é provável que, além dos grandes desafios de desenvolvimento (que são essenciais), o papel do Estado deve ser mais sutil agora.

A organização territorial é da responsabilidade do governo, que por si só pode estabelecer macro estratégias de ocupação de espaço, mas essa ocupação não pode passar apenas de variáveis clássicas de Estado soberano (infraestrutura, defesa, gestão e uso de recursos naturais). As políticas regionais quebequenses do fim dos anos 1990, assim como os objetivos de políticas de Lula no Brasil desenham uma arquitetura de desenvolvimento pluralista e projetado, para dizer, em várias escalas (no Brasil) e para o benefício de vários grupos sociais (Quebec). Entre a sociedade civil e os atores privados, o Estado continua a ser o árbitro de arranjos territoriais, bem como de cooperação, conflitos e das relações de dominação que ocorrem (MOR e ALVES, 2015).

Certamente, o presente contexto (progresso tecnológico, reestruturação produtiva, mudança cultural, entre outros) enfatiza o desenvolvimento endógeno (Benko, 1999), que valoriza os atores não-estatais; mas voltou a valorizar os atores territoriais que correspondem a seu projeto de desenvolvimento nacional. De certa maneira, isso lembra que a política de desenvolvimento agora se parece com o desenvolvimento de políticas da sociedade civil "esse 
processo deve promover a ativação de recursos materiais e simbólicos e a mobilização de sujeitos sociais e políticos buscando ampliar o campo de ação da coletividade, aumentando a sua autodeterminação e liberdade de decisão." (BRANDÃO, 2004, p. 70). Neste contexto, Boisier (1996, p. 7) aponta que "ampliação de oportunidades, da liberdade, de opções, de justiça, e de crescente ética nas relações inter-pessoais e, também, em relação ao meio ambiente", "com ou sem crescimento econômico" são para atores locais um real compromisso político. Ele refere-se a construir a fonte política na região (BOISIER, 1996, p. 130).

Agora, para esta construção de uma capacidade política regional, algumas questões se apresentam como essenciais. Em primeiro lugar, lembramos que os desafios das disparidades espaciais são importantes. No caso do Brasil é evidente que existem diferenças marcantes entre o Sul e o Norte e entre o litoral o interior, que vão desde diferenças de níveis de renda, urbanização, até o acesso a serviços básicos, como água e saneamento básico (MACEDO e COÊLHO, 2016). Mas as tensões territoriais também são importantes no Canadá (entre as províncias e dentro de cada uma delas) - mesmo que as soluções políticas dos anos 1960-1970 fossem poderosamente corretivas (multinível federal, Estado-Providência, equalização, etc.).

Então, o desafio da governança multinível do território é essencial, pois tanto a organização do território no Brasil como no Canadá aparenta uma tensão entre a figura reforçada do município e a fragilidade de uma região com potencial político subestimado. Outra questão central nas discussões sobre o uso do território é a questão ambiental. É importante identificar os passivos ambientais existentes no Brasil e no Canadá, onde o ambiente é frequentemente sujeito a exigências. Entre muitas outras, estas questões evocam a democratização do desenvolvimento - a declaração da equidade, da capacidade de ação regional e a de proteção ambiental produzem pressão dos atores territoriais, sociais ou ambientais.

Vamos terminar com uma postura crítica final sobre a democratização do desenvolvimento dizendo que, se a participação da comunidade é vista como uma força política no Quebec, esta deve ser tomado com cautela. Na verdade, a regionalização não permitiu a criação de um verdadeiro espaço de debate entre aqueles que governam e os governados, para desencadear uma discussão crítica para todos os cidadãos (THÉRIAULT, 1996; HABERMAS, 1993). Em outras palavras, embora haja a participação comunitária influenciando a implementação de políticas públicas territoriais, a participação comunitária envolve sempre uma luta para mobilizar todos os cidadãos da comunidade. A democracia territorial continua a ser uma luta política incessante. 


\section{Referências}

ACSELRAD, Henri. Sustentabilidade e articulação territorial do desenvolvimento brasileiro. In: /I Seminário Internacional sobre Desenvolvimento Regional. Santa Cruz do Sul, RS, 2008.

AZOULAY, Gérard, Les théories du développement. Rennes, Presses Universitaires de Rennes, 2002.

BANDEIRA, PEDRO. Contribuição dos COREDES/RS para o debate sobre a Política Nacional de Desenvolvimento Regional. In: Observando o Desenvolvimento Regional Brasileiro: processos, políticas e planejamento. Santa Cruz do Sul: EDUNISC, 2013.

BENKO, Georges. Economia, espaço e globalização: na aurora do século XXI. Tradução: Antônio de Pádua Danesi. 2. ed. São Paulo: Hucitec, 1999.

BOUDEVILLE, Jacques-R. Les spaces économiques. Press Universitaires de France, Paris, 1970.

BOISIER, Sergio. Em busca do esquivo Desenvolvimento Regional: entre a caixa-preta e o projeto político. Planejamento e Políticas Públicas, n. 13 (1996). Disponível em:

http://189.21.130.9/ppp/index.php/PPP/article/viewFile/135/137. Acesso em: 20 mar. 2019.

BRANDÃO, Carlos. A. Teorias, estratégias e políticas regionais e urbanas recentes: anotações para uma agenda de desenvolvimento territorializado. Revista Paranaense de Desenvolvimento, Curitiba, n. 107, p. 57-76, jul./dez. 2004.

. BRANDÃO, Carlos. Pactos em territórios: escalas de abordagem e ações pelo desenvolvimento. Revista Organizações \& Sociedade, Campinas, SP, v. 15, n. 45, p. 145-157, 2008.

BRASIL. Constituição da República Federativa do Brasil. Distrito Federal: Senado Federal, 1988.

. BRASIL; Ministério da Integração Nacional. Disponível em < http://www.mi.gov.br/>. Acesso em: 10 de mai. 2019.

BRODIE Janine. The New Political Economy of Regions dans Wallace Clément (dir.), Understanding Canada: Building on the new Canadian political economy, McGill-Queen's University Press, p. 240-261, 1996.

BULOS, Uadi Lammêgo. Curso de direito constitucional. 7. ed. São Paulo: Saraiva, 2012.

COTÉ, D. Développement communautaire et rapports sociaux de sexe: essai d'analyse sur toile de fond régionale. In: D. CÔTÉ et al. (org). Du local au planétaire: réflexions et pratiques de femmes en dévelop-pement régional. Montréal, Remue-ménage, 1995, p. 109-133.

CÔTÉ, D.; SIMARD, É. Local Governance and Social Movements in Québec: The Perverse Effects of Corporate Culture. In: D. CROWTHER; A.-M. DAVILA-GOMEZ (org.). Human Dignity and Managerial Responsibility. London, Gower, 2011.

CÔTÉ, L.; LÉVESQUE, B.; MORNEAU, G. L'évolution du modèle québécois de gouvernance: le point de vue des acteurs. Politique et Sociétés, 26(1):3-26, 2007.

CÔTÉ, Denyse; SIMARD, Étienne. Inovações sociais e governança regional no Quebec: que lugar resta aos novos movimentos sociais? Ciências Sociais Unisinos, São Leopoldo, Vol. 47, N. 1, p. 25-33, jan/abr 2011. 
CÔTÉ, D.; SIMARD, É. Local Governance and Social Movements in Québec: The Perverse Effects of Corporate Culture. In: D. CROWTHER; A.-M. DAVILA-GOMEZ (org.). Human Dignity and Managerial Responsibility. London, Gower, 2011.

DURAN, P.; THOENIG, J. C. L'Etat et la gestion publique territoriale. Revue Française de Science Politique, v. 46, n. 4, 1996.

ETGES, Virgínia Elisabeta; DEGRANDI, José Odim. Desenvolvimento regional: a diversidade regional como potencialidade. Revista Brasileira de Desenvolvimento Regional, Blumenau, 1 (1), P. 85-94, OUTONO DE 2013. Disponível em: < http://proxy.furb.br/ojs/index.php/rbdr>. Acesso em: 10 mai. 2019.

EVANS, Peter B. Análise do Estado no mundo neoliberal: uma abordagem institucional comparativa. Revista de Economia Contemporânea, no 4, jul-dez, 1998.

FURTADO, C. A economia latino-americana: formação histórica e problemas contemporâneos. 4. ed. São Paulo: Companhia das Letras, 2007.

HAMEL, P.; JOUVE, B. Un modèle québécois? Gouvernance et participation dans la gestion publique. Montréal, Les Presses de l'Université de Montréal, 2006.

HABERMAS, J. L'espace public: archéologie de la publicité comme dimension constitutive de la société bourgeoise. Paris, Payot. 1993

HIRSCHMAN, Albert O. The strategy of economic development. New Haven: Yale University Press, 1958.

IPEA - Instituto de Pesquisa Econômica Aplicada. 1995-1998: Quatro Anos de Transformações; Brasilia: IPEA; 1999.

JENSON, Jane. Different' but not 'exceptional': Canada's permeable fordismo. Canadian Review of Sociology/Revue canadienne de sociologie, vol. 26, n 1, p. 69-94, 1989.

KLEIN, Juan-Luis. Mondialisation et État-nation: la restructuration territoriale du systèmemonde. IN: KLEIN, Juan-Luis; LAURIN, Suzanne (Org.). L'éducation géographique: formation du citoyen et conscience territoriale, Québec, Presses de l'Université du Québec, p. 55-92, 1999.

LAFONTAINE, Danielle. Politiques territoriales. Pour um modele partenarial décentralisé. La Société québécoise et ses régions, horizon 2025. Leurs impératifs, leur organization. In: LAFONTAINE, Danielle; JEAN, Bruno. Territoires et fonctions: Tome1. Des politiques aux théories: Les modèles de développement regional et de gouvernance on débats. Rimouski: GRIDEQ, 2005.

LÉVESQUE Benoît; MAGER Lucie. L'institutionnalisation des nouvelles dynamiques de concertation locale et régionale au Québec: les acteurs sociaux à la recherche d'une stratégie gagnante. IN: ALAIN, Gagnon; ALAIN, Noël (Org.). L'espace québécois. Montréal, Les Éditions Québec/Amérique, p. 106-135, 1995.

LIMA, Ana Carolina da Cruz; SIMÕES, Rodrigo Ferreira. Teorias do desenvolvimento regional e suas implicações de política econômica no pós-guerra: o caso do Brasil.

http://www.cedeplar.ufmg.br/pesquisas/td/TD\%20358.pdf. Revista de Desenvolvimento Econômico. Vol. 12, n. 21. Belo Horizonte: UFMG/Cedeplar, 2009.

MACEDO, Fernando Cézar de; COÊLHO, Vitarque Lucas Paes. A Política Nacional de Desenvolvimento Regional - PNDR e os Fundos Constitucionais de Financiamento. In: ETGES, 
Virgínia Elisabeta; CADONÁ, Marco André. Globalização em Tempos de Regionalização: Repercussões no Território. Santa Cruz do Sul: EDUNISC, 2016.

MAGALHÃES, José Luiz Quadros de. A necessidade de revisão do papel do Senado na democracia representativa brasileira - ou sua extinção. In BARACHO JÚNIOR, José Alfredo de Oliveira (coord). Constituição e democracia: aplicações. Belo Horizonte: Fórum, 2009.

MINISTÉRIO DA INTEGRAÇÃO/IICA. 2006. Documento base para a definição da Política Nacional de Ordenamento Territorial - PNOT. Versão Preliminar, [Online], Disponível em:

http://www.mi.gov.br/c/document library/get file?uuid=45546192-e711-497a-832307244ee574ce\&groupld=24915. Acesso em: 20 mar. 2019.

MOR, Klara Anna Maria Kaiser; ALVES, Cíntia de Souza. Arqueologia da PNOT: a incorporação do ideário de território e políticas territoriais no brasil contemporâneo. In: XVI ENANPUR. Anais... Belo Horizonte, 2015.

MYRDAL, Gunnar. Economic theory and under-developed regions. Gerald Duckworth \& CO. LTD: London, 1957.

NORTH, Douglass C. Teoria da localização e crescimento econômico regional. In: Schwartzman, J. Economia regional: textos escolhidos. Cedeplar, Belo Horizonte, 1977.

PERROUX, François. A Economia do século XX. Porto: Herder, 1967.

PIKE A.; TOMANEY J.; COOMBES M.; MCCARTHY A. Governing uneven development: the politics of local and regional development in England. In: Bellini, N., Danson, M., Halkier, H, ed. Regional Development Agencies: The Next Generation? Networking, Knowledge and Regional Policies. London: Routledge, 2012, pp.102-121.

PIKE, A.; RODRÍGUEZ-POSE, A.; TOMANEY, J. Local and regional development. London: Routledge, 2006.

SENRA, Kelson Vieira. Políticas Federais de Desenvolvimento Regional no Brasil: uma análise comparada dos Períodos Pós-Guerra (1945-1964), Pós-Golpe Militar (1964-1988) e PósConstituição Federal de 1988 (1988-2009). 2009. 128 f. Dissertação (Programa de PósGraduação em Geografia - Mestrado e Doutorado) - Universidade de Brasília, Santa Cruz do Sul, 2009.

SILVA, José Afonso da. Curso de direito constitucional positivo. São Paulo: Malheiros, 2012.

THÉRIAULT, J.Y. De la critique de l'État à la reviviscence de la so-ciété civile. In: S. PAQUEROT (org.), L'État aux orties? Montréal, Écoso-ciété, p. 141-150. 1996. 